\title{
Visual acuity recovery due to anterior segment reconstruction after severe bilateral open globe injury - case report
}

\author{
Dorota Kopacz* and Piotr Maciejewicz \\ Department of Ophthalmology, Medical University of Warsaw, Poland
}

\begin{abstract}
Open globe injuries are one of the major causes of visual impairment and blindness. Achieving useful visual acuity depends on several factors such as initial visual acuity, presence of relative afferent pupillary defect, mechanism and severity of injury, involvement of ocular structures and proper, prompt diagnosis and treatment. We present a case of 48-year-old man with bilateral open globe injury. Severity of the trauma and poor visual acuity were detrimental prognostic factors for visual acuity outcome. Within long-term follow-up with additional surgery procedures of both eyes we have reached a significant visual acuity improvement.
\end{abstract}

\section{Introduction}

Open globe injuries (OGIs) are one of the major causes of visual impairment and blindness. Negrel et al. [1] reported that worldwide, as a consequence of OGIs, there are 1.6 million blind people, 2.3 million with bilateral low vision and 19 million with unilateral blindness or low vision. Ocular traumas are one of leading indications for enucleation [2-4]. The burden of blindness effects both quality of life and productivity of subjects [5]. Achieving useful visual acuity depends on several factors, such as presenting visual acuity (VA), presence of a relative afferent pupillary defect (RAPD), mechanism and severity of injury, involvement of ocular structures (wound size and location, lens damage, hyphema, vitreal hemorrhage, retinal damage) and proper, prompt diagnosis and treatment [5-8]. We present a case of severe bilateral open globe injury in which - in spite of many detrimental factors - after long therapy we have reached improvement of visual acuity.

\section{Case report}

48-year-old man was admitted during emergency because of bilateral OGI; car window cut both eyeballs and skin of nose. On admission: Vod $=$ hand motion(HM) Vos = questionable light perception(LP). Oedema, haematoma and small wounds of upper lids. Right eye (RE): Congestion of conjunctiva. Cornea with horizontal wound in the central part and vertical at the nasal part of limbus. Hyphema. No possibility to examine other eye structures. Left Eye (LE): Congestion of conjunctiva. Cornea with horizontal wound in the central part and prolapsed iris and vitreus. Intraocular haemorrhage. No possibility to examine other eye structures. Ultrasound examination (USG) revealed: RE: no pathologies with lens and posterior eye segment. LE: lack of lens, intraocular and subrerinal haemorrhages (Figure 1).

Immediate surgical procedures were performed: RE: corneal wounds were sutured, LE: corneal wound was sutured, prolapsed tissues were cut, foreign body was removed from anterior chamber. Wounds of the nasal and lid skin were sutured. Intravenous antibiotic and steroid therapy were administrated. Topical antibiotics, steroids and cycloplegics were started on postoperative day 1 .

Patient was discharged with Vod $=0.5 / 50$ Vos $=$ Fingers Counting (FC). RE: Congestion. Corneal wounds sutured, hyphema of the lower part of anterior chamber, oval pupil with synechiae, lens opacification. LE: Congestion. Corneal wound sutured. Intrabulbar blood clot mixed with vitreus. Posterior segments not available for examination. USG showed RE: no pathologies of posterior eye segment, LE: absorption of vitreal and subretinal haemorrhages (Figure 2).

Nine months later we started surgical procedures to improve visual acuity. At that moment: monovision, Vod $=2.5 / 50 \mathrm{sc}$ but $0.4 \mathrm{cc}+2.0$ Dsph Snod $=0.75 \mathrm{cc}+5.0$ Dsph (looking over the corneal scar), Vos = $3 / 50 \mathrm{cc}+10.0 \mathrm{Dsph}$ Snos $=3.0 \mathrm{cc}+13.0 \mathrm{Dsph}$ (looking over the corneal scar). RE: horizontal scar of central cornea with anterior synechiae. Lens opacification. No pathological changes at the posterior segment of the eye. LE: horizontal scar of central cornea. Aniridia. Aphakia. Epiretinal membrane (ERM) of the posterior pole (Figure 3).

Since that time some procedures have been performed:

RE: cataract surgery with IOL implantation, penetrating keratoplasty with iris reconstruction, penetrating keratoplasty (twice)

LE: implantation IOL (scleral fixation) with artificial iris, trabeculectomy, penetrating keratoplasty

Visual acuity has changed: nowadays Vod $0.5 \mathrm{cc}-5.0=-1.25$ ax 30 Snod $=0.5 c c-2.5=-1.25$ ax 30, Vos $=0.1 c c-2.25=4.0$ ax $80 \mathrm{Sn}$ os $=$

${ }^{*}$ Correspondence to: Dorota Kopacz, Department of Ophthalmology, Medical University of Warsaw, 02-005 Warsaw, 4 Lindleya str, Poland, E-mail: dr.dk@wp.pl

Key words: open globe injury, corneal wound, aniridia, aphakia, visual outcome, IOL scleral fixation

Received: October 05, 2018; Accepted: October 19, 2018; Published: October 22, 2018 

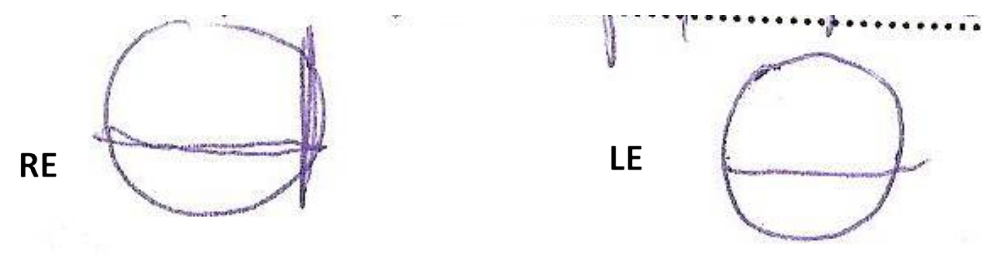

Figure 1a. Data on admission: Schema of the corneal wounds
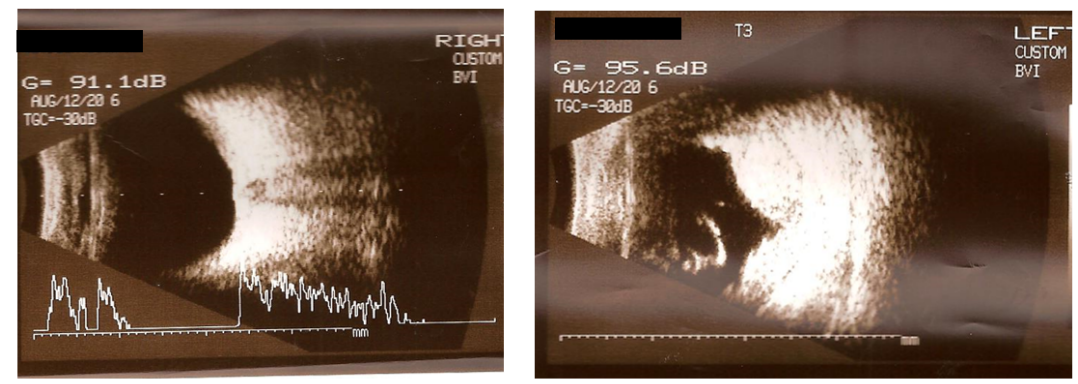

Figure 1b. Data on admission: USG examination
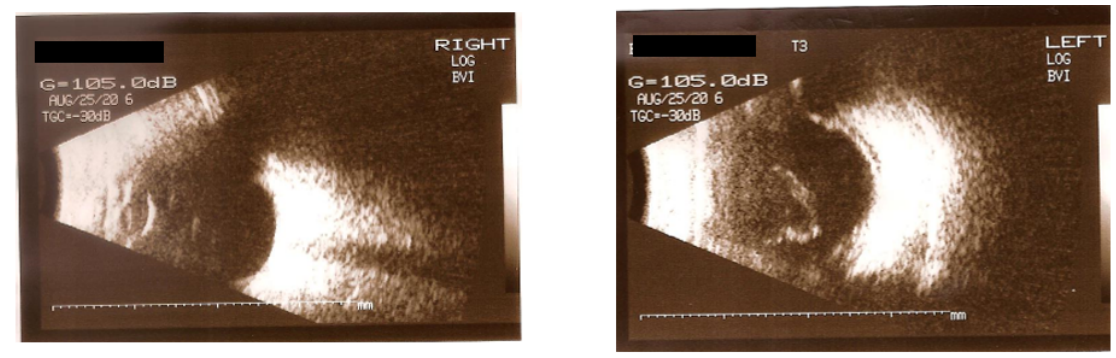

Figure 2. USG examination on discharge day
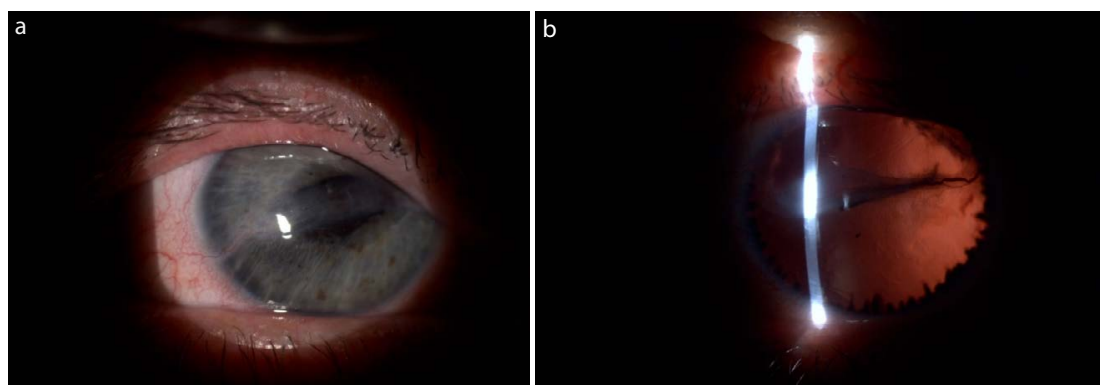

Figure 3. Nine months after trauma.3a). Right eye - horizontal scar of central cornea, anterior synechiae, lens opacification.3b). Left eye - horizontal scar of central cornea, aniridia, aphakia

$1.25 \mathrm{cc}+0.75=-4.0$ ax 80 . LE visual impairment is influenced by ERM of the posterior pole (Figures 4,5 ).

\section{Discussion}

Ocular trauma can result in wide spectrum of ocular morbidity. Severe injuries with NLP carry risk of adverse events and are common indication for enucleation $[9,10]$. For years debate over enucleation of severe injuried eyes with NLP have been existed. With advances in vitreoretinal surgery indication for enucleation is not determined by posttrauma NLP vision alone. Secondary enucleation is carried out for pain (most commonly) or sympathetic ophthalmia $[4,5,10]$. Agraval et al. suggest that the use of modern immunosupressives has improved treatment and control of sympathetic ophthalmia, that's why primary surgical repair should be performed in eyes with NLP
[10]. Moreover, preservation of the globe offers positive psychological impacts on the patients and relatives [10]. In our case report in spite of poor posttrauma VA and severe damage of eyeballs with prolapsed tissues and anterior uvea damage (detrimental prospective prognosis) we decided to undertake repair surgery.

To standardise the description of eye injuries and to link the correct treatment the Ocular Trauma Classification Group developed the Birmingham Eye Trauma Terminology System (BETTS). The classification system was based on: type of injury, grade of it (based on VA at the initial examination) presence of relative afferent pupillary defect (RAPD) and zone of injury. Next, Kuhn et al. developed a prognostic model to predict visual outcomes after OGIs: Ocular Trauma Score (OTS). Data completed during first examination (initial visual acuity and subtract points, type of injury and zone of it) determine 

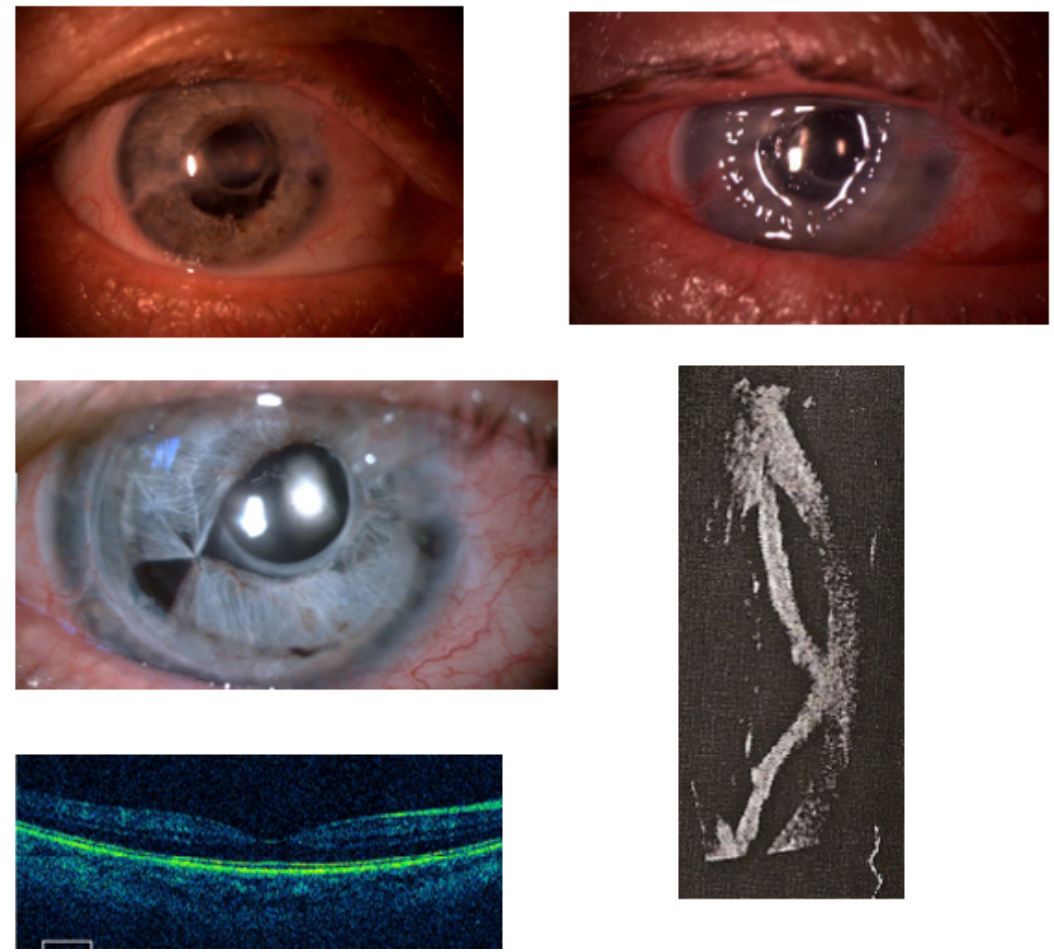

Figure 4. Right eye

1. After lens extraction with artificial lens implantation (anterior synechiae at temporal site)

2. After penetrating keratoplasty with iris plasty

3. After penetrating keratoplasty (last examination)

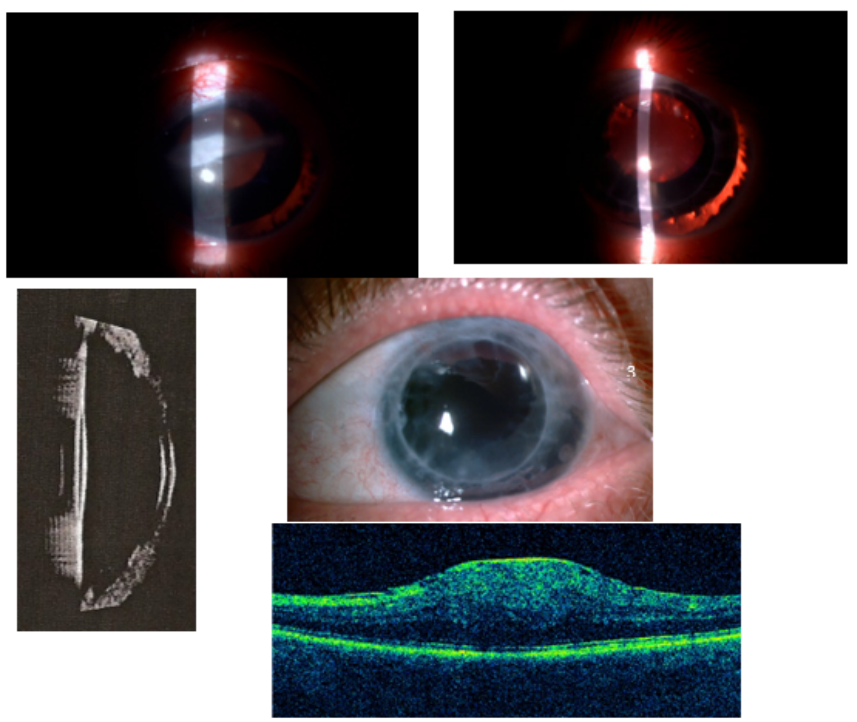

Figure 5. Left eye

1. After implantation IOL (scleral fixation) with artificial iris 2. After penetrating keratoplasty

3. Last examination

prognosis for final VA (prognosis at 6 months) $[11,12,13]$. Presented case was difficult to classify: poor VA, no possibility to check RAPD, perforating injury, prolapsed tissues, haemorrhages, damage of anterior part of uvea, severe trauma of both eyes. We could not base on OTS to predict VA outcome.

The most important complication of OGI is endophthalmitis (6.8\%) $[14,15]$. Severe injury with foreign body, destruction of anterior segment and prolapsed tissues predisposed to endophthalmitis but prompt surgery with systemic antibiotic therapy were enough protection. Secondary glaucoma develops in cases with traumatic cataract, lens ectopia, iris trauma $[15,16]$. In our case report trabeculectomy of LE was performed.

OGIs require significant surgical follow-up [17]. Andreoli et al analised long-term surgical course of patients with OGI: after initial 
open globe repair procedure patients required 2 surgeries on average. The most common included: vitrectomy (ppv and anterior), lensectomy, IOL insertion, anterior chamber washout, vitreoretinal operations. Some of the secondary problems may accumulate in time, e.g. cataract or ERM [17]. Our patient underwent not only cataract surgery but also iris reconstruction, keratoplasty, special IOL insertion.

Despite the progress in surgical techniques in ophthalmology controversies over proper management of OGI are still discussed. Although posttraumatic indications for enucleation have changed, surgical outcome of injured eyes with poor vision vary in published studies $[9,17]$. In our report long term follow-up with a sequence of surgical procedures restored useful visual acuity.

\section{Conclusion}

Ocular trauma causes remarkable morbidity as well as psychological and social stress, economic burden. In spite of standardized scoring systems, useful for prognostication, the final result of treatment may vary according to secondary, accumulated with time problems. OGI require prompt, proper detection and treatment not only results of trauma but also associated complications to restore anatomical integrity of the eyeball and visual acuity. Poor initial VA does not exclude repair surgical treatment, does not mean poor final VA.

\section{References}

1. Négrel AD, Thylefors B (1998) The global impact of eye injuries. Ophthalmic Epidemiol 5: 143-169. [Crossref]

2. Ji YR, Zhu DQ, Zhou HF, Fan XQ (2017) Epidemiologic characteristics and outcomes of open globe injury in Shanghai. Int J Ophthalmol 10: 1295-1300. [Crossref]

3. Farokhfar A, Ahmadzadeh-Amiri A, Sheikhrezaee MR, Gorji MAH, Agaei N (2017) Common Causes of Eye Enucleation among Patients. J Nat Sci Biol Med 8: 150-153. [Crossref]

4. Savar A, Andreoli MT, Kloek CE, Andreoli CM (2009) Enucleation for open globe injury. Am J Ophthalmol 147: 595-600. [Crossref]
5. Fujikawa A, Mohamed YH, Kinoshita H, Matsumoto M, et al. (2018) Visual outcomes and prognostic factors in open-globe injuries. BMC Ophthalmol 18: 138. [Crossref]

6. Yucel OE, Demir S, Niyaz L, Sayin O, Gul A, et al. (2016) Clinical characteristics and prognostic factors of scleral rupture due to blunt ocular trauma. Eye (Lond) 30: 16061613. [Crossref]

7. Page RD, Gupta SK, Jenkins TL, Karcioglu ZA (2016) Risk factors for poor outcomes in patients with open-globe injuries. Clin Ophthalmol 10: 1461-1466. [Crossref]

8. YaÅŸa D, Erdem ZG, Demircan A, Demir G, AlkÄ \pm n Z (2018) Prognostic value of ocular trauma score for open globe injuries associated with metallic intraocular foreign bodies. BMC Ophthalmol 18: 194. [Crossref]

9. Baban TA, Sammouh FK, ElBallous HM, Warrak EL (2015) Complete Visual Rehabilitation in a Patient with No Light Perception after Surgical Management of a Penetrating Open-Globe Injury: A Case Report. Case Rep Ophthalmol 6: 204-209. [Crossref]

10. Agrawal R, Wei HS, Teoh S (2012) Predictive factors for final outcome of severely traumatized eyes with no light perception. BMC Ophthalmol 12: 16. [Crossref]

11. Kunh F, Morris R, Mester V, Witherspoon CD. Terminology of mechanical injuries:the Birmingham Eye Trauma Terminology (BETT). http://www.springer.com/978-3-54033824-6

12. Scott R (2015) The Ocular Trauma Score. Community Eye Health 28: 44-45. [Crossref]

13. Agraval R, Ho SW, Teoh S (2013) Pre-operative variables affecting final vision outcome with critical review of ocular trauma classification for posterior open globe (zone III) injury. Indian J Ophthalmol 61: 541-545.

14. Essex RW, Yi Q, Charles PG, Allen PJ (2004) Post-traumatic endophthalmitis. Ophthalmology 111: 2015-2022. [Crossref]

15. Cãciulã D, Gavris M, Tãmãsoi I (2017) Penetrating corneal wound with traumatic cataract and intraocular foreign body - case report. Romanian J Ophthalmol 61: 54-59.

16. Sihota R, Sood NN, Agarwal HC (1995) Traumatic glaucoma. Acta Ophthalmol Scand 73: 252-254. [Crossref]

17. Andreoli MT, Andreoli CM (2012) Surgical rehabilitation of the open globe injury patient. Am J Ophthalmol 153: 856-860. [Crossref]

Copyright: $\odot 2018$ Kopacz D. This is an open-access article distributed under the terms of the Creative Commons Attribution License, which permits unrestricted use, distribution, and reproduction in any medium, provided the original author and source are credited. 